\title{
Association of Ramadan daytime fasting with ocular surface inflammation and dry eye
}

\author{
Brian K. Armstrong $(\mathbb{D} \cdot$ Ivana Romac Coc $\cdot$ Prateek Agarwal $\cdot$ Scott Smith • \\ Samuel Navon
}

Received: 21 March 2019/Accepted: 27 May 2019/Published online: 31 May 2019

(C) The Author(s) 2019

\begin{abstract}
Purpose Despite the widespread practice of fasting, there are no studies looking at ocular surface inflammation, specifically matrix metalloproteinase 9 (MMP-9) testing, during fasting. In this prospective study, we wanted to evaluate the effect of Ramadan fasting on the level of tear film MMP-9 as well as other standard indicators of dry eye disease.

Methods Forty healthy patients without history of ocular disease were tested before and toward the end of Ramadan. Each patient was assessed at each timepoint for tear film MMP-9 positivity as measured by a commercially available test (InflammaDry; Quidel Corp., San Diego, CA, USA) which detects MMP-9 levels of more than $40 \mathrm{ng} / \mathrm{ml}$. Ocular surface disease index (OSDI) scores, tear breakup time (TBUT), Schirmer I test (S1T) and corneal fluorescein staining (CFS) were also evaluated at each timepoint. Results InflammaDry was positive in 10 patients (25\%) prior to Ramadan and 21 patients (52.5\%) during Ramadan fasting, and this change was statistically significant $(p=0.02)$. Mean TBUT decreased from $7 \mathrm{~s}$ prior to Ramadan to $5.3 \mathrm{~s}$ during Ramadan fasting, and this change was statistically significant
\end{abstract}

B. K. Armstrong $(\varangle) \cdot$ I. R. Coc $\cdot$ P. Agarwal .

S. Smith - S. Navon

Cleveland Clinic Abu Dhabi - Eye Institute, Al Maryah

Island - Sowwah Square, PO Box 112412, Abu Dhabi,

United Arab Emirates

e-mail: ArmstrB@ClevelandClinicAbuDhabi.ae $(p=0.01)$. OSDI, CFS and S1T did not show any statistically significant changes ( $p>0.05$ for all).

Conclusion Ramadan fasting has a significant impact on TBUT and ocular surface inflammation detected by Inflamma Dry testing. Patients who suffer from dry eye disease and those who develop symptoms during Ramadan are advised to consult with a physician before or during Ramadan fasting.

Keywords InflammaDry - Ocular surface inflammation $\cdot$ Dry eye syndrome $\cdot$ Ramadan $\cdot$ Fasting

\section{Introduction}

Fasting is practiced widely for both health benefits and spiritual and religious purposes. Religious daytime fasting is practiced by millions of Muslims during the month of Ramadan and involves complete abstinence from food and water from sunrise to sunset. During this month, alterations in dietary composition and sleep schedules are also common [1,2]. Significant systemic and ophthalmic changes have been observed during Ramadan fasting [3-5]. The latter include ocular biometric alterations [5-8] and changes in tear film protein composition, osmolarity and secretion [9-12].

The role of matrix metalloproteases (MMP) as a reactive component in ocular surface disease is well established. In particular, MMP-9 is a proteolytic 
enzyme produced by epithelial cells and is elevated in patients with ocular surface diseases, including dry eye syndrome [13-18]. MMP-9 stimulates the production of inflammatory cytokines and other mediators that further augment the inflammatory cycle [19-25]. The significant and reproducible elevation of MMP-9 in patients with dry eye has led to the development of a simple point-of-care commercially available assay for its detection (InflammaDry; Quidel Corp., San Diego, CA, USA) [13-15, 26]. Despite the widespread practice of fasting, there are no studies looking at the results of InflammaDry testing during fasting. In this study, we measured the levels of tear MMP-9 as well as other standard indicators of dry eye disease in subjects before and during Ramadan fasting.

\section{Methods}

All procedures performed were in accordance with the ethical standards and approval of the Cleveland Clinic Abu Dhabi institutional review board and the 1964 Helsinki Declaration. Written consent was obtained from all participants after explanation of the protocol in Arabic or English according to patient preference. This study incorporated two timepoints and was carried out from May to June 2018. The first nonfasting timepoint was in the week preceding Ramadan. The second fasting timepoint was in the afternoon between noon and $5 \mathrm{pm}$ during either the third or fourth week of Ramadan which occurred from 16 May to 14 June 2018. Fifty participants were initially enrolled in this study for the first timepoint. Inclusion criteria included patients above the age of 18 years that would be fasting (food and fluid) from dawn to dusk during the month of Ramadan. Exclusion criteria included patients having history of systemic diseases including diabetes mellitus, collagen/vascular tissue disease, thyroid disease, rosacea, diabetes insipidus, diarrhea or vitamin A deficiency; patients taking systemic medications including anticholinergics, betablockers, antidepressants, antihistamines, antiparkinsonians or artificial hormones such as androgens or estrogens; patients with a known history of dry eye disease; patients with ocular surface diseases including blepharitis, trachoma and allergic conjunctivitis; patients with a history of previous ocular surgery; and patients who had worn contact lenses within 1 week of the exam. The same clinical tests were performed at each timepoint.

Subjective symptoms were measured using the Ocular Surface Disease Index (OSDI) survey. This is a self-administered 12-item questionnaire designed to provide a global measure of dry eye. The OSDI score ranges from 0 to 100 , where a score of 0 indicates no disability and 100 indicates extreme disability.

InflammaDry testing was performed to determine if patients exhibited elevated tear film levels of MMP-9. A trained ophthalmic nurse performed the test according to the manufacturer's instructions on each eye separately. To perform the test, the nurse collected a tear sample from the patient's palpebral conjunctiva until the sampling fleece was saturated. The test cassette was assembled and dipped into the provided test buffer solution for activation. After $10 \mathrm{~min}$, the test values were read. The presence of one blue line and one red line of any intensity in the test result window indicated a positive test result (MMP$9 \geq 40 \mathrm{ng} / \mathrm{mL}$ ). One blue line indicated a negative test result (MMP-9 $<40 \mathrm{ng} / \mathrm{mL}$ ). The subject was considered InflammaDry positive if the testing was positive in either one or both eyes.

Tear film breakup time (TBUT) was evaluated 2 min after instillation of one drop of fluorescein sodium $2 \%$ preservative-free eye solution (Bausch \& Lomb U.K Limited, Surrey, UK) into the inferior fornix. Subjects were instructed to blink, and the precorneal tear film was examined under blue light illumination with a slit lamp biomicroscope. The interval between the blink and the appearance of the first dark spot or discontinuity in the pre-corneal fluorescein-stained tear layer was then recorded in seconds (s).

Corneal fluorescein staining (CFS) was scored according to the Oxford grading scheme. The result was based on the number of dots on a five-point scale: no $\operatorname{dot}=$ grade 0,1 to 5 dots $=$ grade 1,6 to 15 dots $=$ grade 2,16 to 30 dots $=$ grade 3 and $>30$ dots $=$ grade 4 . Additionally, if there was one area of confluence, one point was added. Two points were added if there were $\geq 2$ areas of confluence or if filamentary keratitis was present.

Basal tear secretion (BTS) was measured by performing Schirmer 1 testing (S1T). First, topical anesthetic oxybuprocaine hydrochloride $0.4 \%$ preservative-free eye solution (Bausch \& Lomb U.K Limited, Surrey, UK) was instilled into the inferior 
fornix of each eye. Schirmer test strips (Eagle Vision, Memphis, TN, USA) were then placed within the lower eyelid margin at the junction of the lateral and middle thirds for $5 \mathrm{~min}$. The strip wetting was measured and recorded in millimeters. If complete wetting of the strips occurred before $5 \mathrm{~min}$ and the person administering the test felt that an initial response occurred because of reflex tear secretion (RTS), the test was repeated after taking measures to prevent reflex tearing (i.e., re-anesthetizing the eye and removing any potential irritants). If complete wetting of the strips again occurred before $5 \mathrm{~min}$, the Schirmer score was extrapolated linearly to the 5-min end point.

If signs or symptoms of dry eye were detected at the first examination timepoint, the condition was not treated until after the second examination timepoint so as not to confound the impact of fasting. Patients were instructed not to initiate any oral or topical eye medications or lubricants (including nutritional supplements) during the study.

Statistical analysis was performed using Stata 12.0 statistical software (StataCorp LLC, College Station, Texas). Comparison of the rate of InflammaDry test result positivity assessed during non-fasting and fasting periods was performed using the two-tailed Fisher's exact test. Comparison of the results of the OSDI questionnaire, TBUT, CFS and S1T between the two timepoints was performed using the two-tailed one sample Student's $t$ test.

\section{Results}

The study enrolled 50 patients who were tested at timepoint \#1 (non-fasting). There were 10 patients who did not follow-up for the fasting timepoint \#2 and were thus excluded from the study results. Of the 40 patients who completed testing at both testing timepoints, the mean age was 32 years (range: 23-45 years). Thirteen patients were male, and 27 were female. All testing results are summarized in Table 1.

During Ramadan fasting, there was a statistically significant increase in InflammaDry positive patients from 25 to $52.5 \%(p=0.02)$ (Fig. 1) and a statistically significant decrease in mean TBUT $(p=0.01)$. There were no statistically significant changes in OSDI, CFS or BTS during the study.
During the study (May to June 2018), the climate was quite harsh in Abu Dhabi. The month before Ramadan, the mean temperature and humidity were $33{ }^{\circ} \mathrm{C}$ and $44 \%$, respectively. During the month of Ramadan, the mean temperature and humidity were $35{ }^{\circ} \mathrm{C}$ and $46 \%$, respectively.

\section{Discussion}

Fasting has gained popularity due to its potential benefits for health and longevity [27-30] in addition to the spiritual and religious practices. Fasting results in ketogenesis and promotes potent changes in metabolic pathways and cellular processes. Variations in the types of fasting exist with respect to the length of time and the composition and amount of food and liquid that is restricted and/or permitted. In order to better understand the acute effects of fasting on the ocular surface, we chose to study patients observing fasting during the month of Ramadan because of its relative simplicity-no food or water is permitted between sunrise and sunset for 1 month with no additional dietary restrictions during the remainder of the day.

In our study, InflammaDry testing showed a statistically significant change during Ramadan fasting, wherein the number of InflammaDry positive patients more than doubled. InflammaDry is a pointof-care MMP-9 test and is approved for detecting elevated levels of MMP-9 in tears of dry eye patients [13-18]. Whereas the reported sensitivity and specificity of routine dry eye diagnostic methods, such as the BTS, TBUT, CFS, and OSDI, show a variable sensitivity ranging from 42 to $90 \%$ and specificity ranging from 17 to $89 \%$ [31], InflammaDry's sensitivity of $85 \%$ and specificity of $94 \%$ is superior [15]. As a result of the hyperosmolar stress induced during Ramadan fasting [10, 32, 33], there is a direct proinflammatory effect on the ocular surface epithelium, activating mitogen-activated protein kinases and stimulating secretion of proinflammatory cytokines, chemokines and MMPs [34-36]. Because MMP-9 is induced by all of the primary inflammatory mediators throughout the inflammatory cascade, it has been shown to precede the development of other dry eye signs $[13,14]$.

Among all other dry eye parameters tested in our study, only TBUT showed a statistically significant change. TBUT decreased during Ramadan fasting, 
Table 1 Summary of dry eye testing

\begin{tabular}{llll}
\hline & $\begin{array}{l}\text { Baseline non-fasting } \\
\text { Timepoint \#1, standard } \\
\text { deviation }\end{array}$ & $\begin{array}{l}\text { Ramadan fasting } \\
\text { Timepoint \#2, standard } \\
\text { deviation }\end{array}$ & $\begin{array}{l}\text { Mean } \pm \text {, standard } \\
\text { deviation }\end{array}$ \\
\hline $\begin{array}{l}\text { Number of patients } \\
\text { InflammaDry positivity }\end{array}$ & 40 & 40 & 0.02 \\
$\quad$ (number/total) & $10 / 40$ & $21 / 40$ & $-2.6 \pm 15.2$ \\
$\begin{array}{l}\text { Ocular surface disease index } \\
\quad \text { score }\end{array}$ & $17.7 \pm 18.7$ & $13.2 \pm 18.3$ & $-1.7 \pm 4.1$ \\
$\begin{array}{l}\text { Mean tear film breakup time (s) } \\
\text { Mean corneal staining (grade) }\end{array}$ & $7.0 \pm 3.6$ & $5.3 \pm 3.0$ & $+0.2 \pm 1.9$ \\
Mean Schirmer 1 testing (mm) & $21.0 \pm 9.5$ & $0.8 \pm 1.1$ & $-1.0 \pm 6.9$ \\
\hline
\end{tabular}

Fig. 1 Summary of InflammaDry testing

\section{InflammaDry Testing}

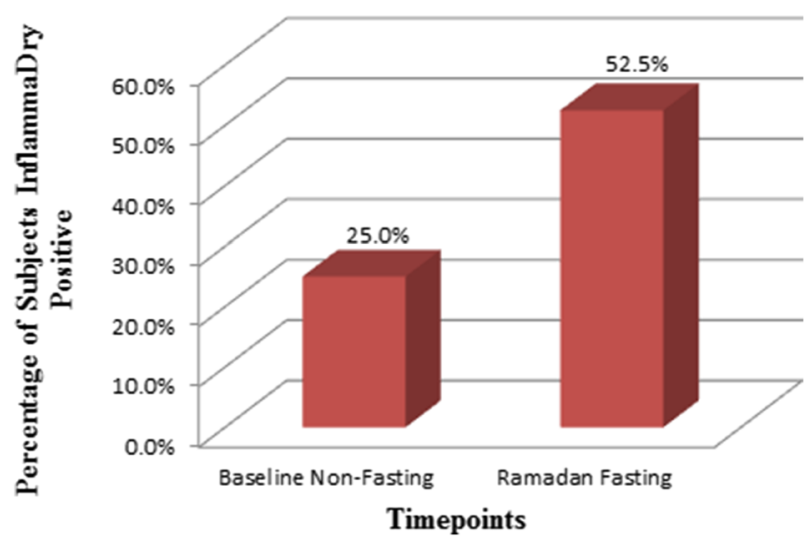

fell in the month of January 1998, and they detected no statistically significant change in TBUT or BTS during Ramadan fasting. Seasonality and latitude are to be considered with regard to both daytime duration and climate. In contrast to these two studies, our study took place in a temperate climate during the summer months from May to June, and our subjects were exposed to a more prolonged fast. During Ramadan in the summer in Abu Dhabi, the mean daily duration of the fast was $13.5 \mathrm{~h}$, compared to approximately $10.5 \mathrm{~h}$ for winter and fall in Istanbul.

This study has several limitations. First, the number of subjects was not large enough to analyze individual variables between the InflammaDry positive and negative patients. Second, only one examination in the afternoon in the 3rd or 4th week of Ramadan fasting was performed; therefore, diurnal changes could not be evaluated. Third, it was not possible to 
isolate the impact of fasting versus lifestyle and sleep changes in this study because these variables are introduced concurrently during Ramadan.

Significant sleep changes occur during Ramadan as a result of more stringent accordance with tenants such as prayer and religious observance. During Ramadan, Muslims tend to become more nocturnal and sleep less. These findings were confirmed by BaHammam et al. [2], who found that bedtime and wake-up times were both delayed and there was a significant reduction in total sleep time in Saudi Arabia. In that study, mean total sleep time decreased from $5.9 \mathrm{~h}$ preRamadan to $4.8 \mathrm{~h}$ during week 2 of Ramadan $(p<0.001)$. This is significant because simply shifting to a nocturnal schedule might alone have an impact on the tear film. A study by Makateb and Torabifard [37] found that night shift workers have increased tear film instability and experience exacerbation of dry eye symptoms. We did not study sleep patterns in our patients, but many of our female patients endorsed sleeping 50\% less than normal during Ramadan due to increased food preparation responsibilities.

Several clinical recommendations arise from our findings. First, patients without signs or symptoms of dry eye should be made aware of the potential benefits of lubrication should symptoms develop during periods of fasting. Second, for patients with preexisting dry eye disease who intend to observe Ramadan fasting, consideration could be given to escalating treatment based on the treatment stepladder approach from the International Dry Eye Workshop management and therapy guidelines [38]. These patients may be ideal candidates for initiating anti-inflammatory systemic or topical medications. Nutritional supplementation with omega- 3 fatty acids has been shown to have an anti-inflammatory effect [39, 40]. Corticosteroids and tetracycline-class antibiotics inhibit MMP activity and improve ocular surface inflammation [41]. There are also a variety of corticosteroid-sparing antiinflammatory ophthalmic drops that have been shown to be effective and safe for long-term or even cyclical use in patients with dry eye and dry eye-related inflammation. Cyclosporine A $0.05 \%$ (Restasis; Allergan, Irvine, CA) is an ophthalmic drop that has been shown to be effective as a treatment for the signs of dry eye syndrome [42] and as an modulator of inflammatory markers on the ocular surface $[43,44]$. Cyclosporine A $0.05 \%$ works as an inhibitor of $\mathrm{T}$ cell proliferation and apoptosis of ocular surface cells [45].
In a study by Gürdal et al., Cyclosporine A $0.05 \%$ was shown to significantly decrease MMP-9 expression in conjunctival epithelial cells of thyroid orbitopathy patients with dry eye syndrome [46]. Lifitegrast 5\% (Xiidra; Shire, Lexington, MA) is a more recently available ophthalmic drop that has been shown to be effective in the treatment of the signs and symptoms of dry eye disease [47, 48]. Lifitegrast works as a lymphocyte function-associated antigen-1 (LFA-1) antagonist that blocks binding of intercellular adhesion molecule-1 to LFA-1, which facilitates cellmediated inflammation associated with DED, including honing dendritic cells to $\mathrm{T}$ cells and subsequent $\mathrm{T}$ cell activation, differentiation, migration, retention and expression on the ocular surface [49]. Either of these corticosteroid-sparing anti-inflammatory ophthalmic drops could be considered in the treatment of ocular surface inflammation related to Ramadan fasting. Lastly, lacrimal gland neurostimulation is a promising new alternative therapy in patients whereby electrical stimulation of the anterior ethmoid nerve increases aqueous tear production [50]. This may play a role for patients within the Muslim community who are concerned that systemic uptake of eye drops will break their fast. The current study is too small to recommend routine supplemental lubrication to all patients intending to observe Ramadan.

Patients may be at risk of exacerbation of dry eye and ocular surface inflammation during Ramadan fasting. The mix of extrinsic factors (i.e., day length, desiccating environment, ultraviolet light exposure) and intrinsic factors (i.e., daytime fasting, sleep schedule disturbances) that can affect tear film quality can make it difficult to ascribe a single cause. Patients who suffer from dry eye disease are advised to consult a physician in preparation for Ramadan fasting.

Acknowledgements We thank Sherry Ann Santarina, RN, CCRN, MPH (Research Nurse Coordinator at Cleveland Clinic Abu Dhabi) for assisting with patient recruitment and data collation.

Funding There was no funding source(s) for this study.

\section{Compliance with ethical standards}

Conflict of interest The authors declare that they have no conflict of interest.

Ethical approval All procedures performed were in accordance with the ethical standards and approval of the Cleveland 
Clinic Abu Dhabi institutional review board and the $1964 \mathrm{Hel}-$ sinki Declaration.

Informed consent Written consent was obtained from all participants after explanation of the protocol in Arabic or English according to patient preference.

Open Access This article is distributed under the terms of the Creative Commons Attribution 4.0 International License (http:// creativecommons.org/licenses/by/4.0/), which permits unrestricted use, distribution, and reproduction in any medium, provided you give appropriate credit to the original author(s) and the source, provide a link to the Creative Commons license, and indicate if changes were made.

\section{References}

1. Shadman Z, Poorsoltan N, Akhoundan M, Larijani B, Soleymanzadeh M, Akhgar Zhand C et al (2014) Ramadan major dietary patterns. Iran Red Crescent Med J. https://doi. org/10.5812/ircmj.16801

2. BaHammam AS, Alaseem AM, Alzakri AA, Sharif MM (2013) The effects of Ramadan fasting on sleep patterns and daytime sleepiness: an objective assessment. J Res Med Sci 18:127-131

3. Meo SA, Hassan A (2015) Physiological changes during fasting in Ramadan. J Pak Med Assoc 65:S6-S14

4. Hanif W, Lessan N, Basit A (2016) Physiology of ramadan fasting. Diabetes and ramadan practical guidelines. International Diabetes Federation, Brussels, pp 29-39

5. Sedaghat MR, Heravian J, Askarizadeh F, Jabbarvand M, Nematy M, Rakhshandadi T et al (2017) Investigation of the effects of Islamic fasting on ocular parameters. J Curr Ophthalmol 29:287-292. https://doi.org/10.1016/j.joco. 2017.07.005

6. Nowroozzadeh MH, Mirhosseini A, Meshkibaf MH, Roshannejad J (2012) Effect of Ramadan fasting in tropical summer months on ocular refractive and biometric characteristics. Clin Exp Optom 95:173-176. https://doi.org/10. 1111/j.1444-0938.2011.00698.x

7. Sarici AM, Yuksel Elgin C, Dikkaya F (2016) Effect of fasting on corneal biomechanical and structural parameters. Curr Eye Res 41:908-912. https://doi.org/10.3109/ 02713683.2015.1080279

8. Baser G, Cengiz H, Uyar M, Seker UE (2016) Diurnal alterations of refraction, anterior segment biometrics, and intraocular pressure in long-time dehydration due to religious fasting. Semin Ophthalmol 31:499-504. https://doi. org/10.3109/08820538.2014.962179

9. Sariri R, Varasteh A, Sajedi RH (2010) Effect of Ramadan fasting on tear proteins. Acta Med (Hradec Kral) 53:147-151. https://doi.org/10.14712/18059694.2016.74

10. Koktekir BE, Bozkurt B, Gonul S, Gedik S, Okudan S (2014) Effect of religious fasting on tear osmolarity and ocular surface. Eye Contact Lens 40:239-242. https://doi. org/10.1097/ICL.0000000000000044

11. Kerimoglu H, Ozturk B, Gunduz K, Bozkurt B, Kamis U, Okka M (2009) Effect of altered eating habits and periods during Ramadan fasting on intraocular pressure, tear secretion, corneal and anterior chamber parameters. Eye 24:97-100. https://doi.org/10.1038/eye.2009.96

12. Rabbanikhah Z, Javadi M, Karimian F, Rouhani MR, Zamani M, Banaee T et al (2007) Effect of religious fasting on basal tear secretion, tear break up time and intraocular pressure. Bina 12:485-491

13. Chotikavanich S, de Paiva CS, Li DQ, Chen JJ, Bian F, Farley WJ et al (2009) Production and activity of matrix metalloproteinase-9 on the ocular surface increase in dysfunctional tear syndrome. Investig Ophthalmol Vis Sci 50:3203-3209. https://doi.org/10.1167/iovs.08-2476

14. Sambursky R, Davitt Iii WF, Friedberg M, Tauber S (2014) Prospective, multicenter, clinical evaluation of point-ofcare matrix metalloproteinase- 9 test for confirming dry eye disease. Cornea 33:812-818

15. Sambursky R, Latkany R, Tauber S, Starr C, Friedberg M, Dirks MS et al (2013) Sensitivity and specificity of a pointof-care matrix metalloproteinase 9 immunoassay for diagnosing inflammation related to dry eye. JAMA Ophthalmol 131:24-28

16. Sambursky R (2016) Presence or absence of ocular surface inflammation directs clinical and therapeutic management of dry eye. Clin Ophthalmol 10:2337-2343. https://doi.org/ 10.2147/OPTH.S121256

17. Chan TCY, Ye C, Chan KP, Chu KO, Jhanji V (2016) Evaluation of point-of-care test for elevated tear matrix metalloproteinase 9 in post-LASIK dry eyes $1188-1191$. https://doi.org/10.1136/bjophthalmol-2015-307607

18. Lanza NL, McClellan AL, Batawi H, Felix ER, Sarantopoulos KD, Levitt RC et al (2016) Dry eye profiles in patients with a positive elevated surface matrix metalloproteinase 9 point-of-care test versus negative patients. Ocul Surf 14:216-223. https://doi.org/10.1016/j.jtos.2015. 12.007

19. Behrens A, Doyle JJ, Stern L, Chuck RS, McDonnell PJ, Azar DT et al (2006) Dysfunctional tear syndrome: a Delphi approach to treatment recommendations. Cornea 25:900-907. https://doi.org/10.1097/01.ico.0000214802. 40313.fa

20. McCollum CJ, Foulks GN, Bodner B, Shepard J, Daniels K, Gross V et al (1994) Rapid assay of lactoferrin in keratoconjunctivitis sicca. Cornea 13:505-508

21. Pflugfelder SC, Jones D, Ji Z, Afonso A, Monroy D (1999) Altered cytokine balance in the tear fluid and conjunctiva of patients with Sjögren's syndrome keratoconjunctivitis sicca. Curr Eye Res 19:201-211

22. Solomon A, Dursun D, Liu Z, Xie Y, Macri A, Pflugfelder SC (2001) Pro- and anti-inflammatory forms of interleukin1 in the tear fluid and conjunctiva of patients with dry-eye disease. Investig Ophthalmol Vis Sci 42:2283-2292

23. Afonso AA, Sobrin L, Monroy DC, Selzer M, Lokeshwar B, Pflugfelder SC (1999) Tear fluid gelatinase B activity correlates with IL-1alpha concentration and fluorescein clearance in ocular rosacea. Investig Ophthalmol Vis Sci 40:2506-2512

24. Pisella P, Goldschild M, De Saint Jean M, Goguel A, Baudouin C (2016) Flow cytometric analysis of inflammatory markers in conjunctival epithelial cells of patients with dry eyes. Franc AND 41:1356-1363

25. Pflugfelder SC (2003) Anti-inflammatory therapy of dry eye. Ocul Surf 1:31-36 
26. Messmer EM, von Lindenfels V, Garbe A, Kampik A (2016) Matrix metalloproteinase 9 testing in dry eye disease using a commercially available point-of-care immunoassay. Ophthalmology 123:2300-2308. https://doi.org/10.1016/j. ophtha.2016.07.028

27. Longo VD, Mattson MP (2014) Fasting: molecular mechanisms and clinical applications. Cell Metab 19:181-192. https://doi.org/10.1016/j.cmet.2013.12.008

28. Catterson JH, Khericha M, Dyson MC, Vincent AJ, Callard R, Haveron SM et al (2018) Short-term, intermittent fasting induces long-lasting gut health and TOR-independent lifespan extension. Curr Biol 28(1714-1724):e4. https://doi. org/10.1016/j.cub.2018.04.015

29. Buffenstein R (2018) A window into extreme longevity; the circulating metabolomic signature of the naked mole-rat, a mammal that shows negligible senescence. GeroScience 40:105-121

30. Zhang S, Ratliff EP, Molina B, El-Mecharrafie N, Mastroianni J, Kotzebue RW et al (2018) Aging and intermittent fasting impact on transcriptional regulation and physiological responses of adult drosophila neuronal and muscle tissues. Int J Mol Sci. https://doi.org/10.3390/ijms19041140

31. Versura P, Frigato M, Cellini M, Mulè R, Malavolta N, Campos EC (2007) Diagnostic performance of tear function tests in Sjogren's syndrome patients. Eye 21:229-237. https://doi.org/10.1038/sj.eye.6702204

32. Kayikçioğlu Ö, Erkin EF, Erakgün T (1998) The influence of religious fasting on basal tear secretion and tear break-up time. Int Ophthalmol 22:67-69. https://doi.org/10.1023/A: 1006119330534

33. Molla AM (2003) Effects on health of fluid restriction during fasting in Ramadan. Eur J Clin Nutr 57:S30-S38. https://doi.org/10.1038/sj.ejcn.1601899

34. Pflugfelder SC, de Paiva CS (2017) The pathophysiology of dry eye disease: what we know and future directions for research. Ophthalmology 124:S4-S13. https://doi.org/10. 1016/j.ophtha.2017.07.010

35. Luo L, Li DQ, Corrales RM, Pflugfelder SC (2005) Hyperosmolar saline is a proinflammatory stress on the mouse ocular surface. Eye Contact Lens 31:186-193. https://doi.org/10.1097/01.ICL.0000162759.79740.46

36. Corrales RM, Stern ME, De Paiva CS, Welch J, Li D-Q, Pflugfelder SC (2006) Desiccating stress stimulates expression of matrix metalloproteinases by the corneal epithelium. Investig Opthalmol Vis Sci 47:3293. https://doi. org/10.1167/iovs.05-1382

37. Makateb A, Torabifard H (2017) Dry eye signs and symptoms in night-time workers. J Curr Ophthalmol 29:270-273. https://doi.org/10.1016/j.joco.2017.05.003

38. Subcommittee T (2007) Management and therapy of dry eye disease: report of the management and therapy subcommittee of the international dry eye workshop. Ocul Surf 5:163-178. https://doi.org/10.1016/S1542-0124(12)70085$\mathrm{X}$

39. James M, Gibson R, Cleland L (2000) Dietary polyunsaturated fatty acids and inflammatory mediator production. Am J Clin Nutr 71:1-6

40. Endres S, Ghorbani R, Kelley VE, Georgilis K, Lonnemann G, van der Meer JW et al (1989) The effect of dietary supplementation with n-3 polyunsaturated fatty acids on the synthesis of interleukin-1 and tumor necrosis factor by mononuclear cells. N Engl J Med 320:265-271. https://doi. org/10.1056/NEJM198902023200501

41. De Paiva CS, Corrales RM, Villarreal AL, Farley WJ, Li D-Q, Stern ME et al (2006) Corticosteroid and doxycycline suppress MMP-9 and inflammatory cytokine expression, MAPK activation in the corneal epithelium in experimental dry eye. Exp Eye Res 83:526-535. https://doi.org/10.1016/j. exer.2006.02.004

42. Rhee MK, Mah FS (2017) Clinical utility of cyclosporine (CsA) ophthalmic emulsion $0.05 \%$ for symptomatic relief in people with chronic dry eye: a review of the literature. Clin Ophthalmol 11:1157-1166. https://doi.org/10.2147/opth. s113437

43. Baudouin C, Brignole F, Pisella P-J, De Saint Jean M, Goguel A (2002) Flow cytometric analysis of the inflammatory marker HLA DR in dry eye syndrome: results from 12 months of randomized treatment with topical cyclosporin A. Adv Exp Med Biol 506:761-769

44. Turner K, Pflugfelder SC, Ji Z, Feuer WJ, Stern M, Reis BL (2000) Interleukin-6 levels in the conjunctival epithelium of patients with dry eye disease treated with cyclosporine ophthalmic emulsion. Cornea 19:492-496. https://doi.org/ 10.1097/00003226-200007000-00018

45. Kunert KS, Tisdale AS, Stern ME, Smith JA, Gipson IK (2000) Analysis of topical cyclosporine treatment of patients with dry eye syndrome: effect on conjunctival lymphocytes. Arch Ophthalmol 118:1489-1496

46. Gürdal C, Genç I, Saraç O, Gönül I, Takmaz T, Can I (2010) Topical cyclosporine in thyroid orbitopathy-related dry eye: clinical findings, conjunctival epithelial apoptosis, and MMP-9 expression. Curr Eye Res 35:771-777. https://doi. org/10.3109/02713683.2010.490320

47. Holland EJ, Luchs J, Karpecki PM, Nichols KK, Jackson MA, Sall K et al (2017) Lifitegrast for the treatment of dry eye disease: results of a phase III, randomized, doublemasked, placebo-controlled trial (OPUS-3). Ophthalmology 124:53-60. https://doi.org/10.1016/j.ophtha.2016.09.025

48. Sheppard JD, Torkildsen GL, Lonsdale JD, D'Ambrosio FA, McLaurin EB, Eiferman RA et al (2014) Lifitegrast ophthalmic solution $5.0 \%$ for treatment of dry eye disease: results of the OPUS-1 phase 3 study. Ophthalmology 121:475-483. https://doi.org/10.1016/j.ophtha.2013.09.015

49. Pflugfelder SC, Stern M, Zhang S, Shojaei A (2017) LFA-1/ ICAM-1 interaction as a therapeutic target in dry eye disease. J Ocul Pharmacol Ther 33:5-12. https://doi.org/10. 1089/jop.2016.0105

50. Friedman NJ, Butron K, Robledo N, Loudin J, Baba SN, Chayet A (2016) A nonrandomized, open-label study to evaluate the effect of nasal stimulation on tear production in subjects with dry eye disease. Clin Ophthalmol 10:795-804. https://doi.org/10.2147/OPTH.S101716

Publisher's Note Springer Nature remains neutral with regard to jurisdictional claims in published maps and institutional affiliations. 